\title{
Divisão de Números Naturais: do saber previsto ao saber efetivamente ensinado em classes do Ensino Fundamental
}

\author{
Natural Numbers Division: from predicted knowledge to knowledge \\ effectively taught in elementary school classes
}

\author{
José André Bezerra da Cruz
}

Rosinalda Aurora de Melo Teles

\begin{abstract}
Resumo: Esse artigo é recorte de uma pesquisa de mestrado acadêmico que adota a noção de transposição didática de Yves Chevallard e objetiva analisar aspectos relacionados ao processo de transposição didática interna da operação de divisão de números naturais no Ensino Fundamental. Para subsidiar a análise das aulas de Matemática de três professores, foi realizado um estudo dos documentos legais do Brasil e do Estado de Pernambuco, análise de livros didáticos para $04^{\circ}, 5^{\circ}$ e $6^{\circ}$ anos e entrevistas com os professores que atuam nesses anos escolares. Nas aulas, o foco de análise foram os diferentes significados da divisão, os procedimentos de cálculo, o tratamento dado ao resto e à interpretação dos resultados obtidos, abordados ou não nas aulas observadas. Ao comparar o saber previsto para ser ensinado e o saber efetivamente ensinado verificou-se mudanças, deformações e lacunas, que poderiam
\end{abstract} acarretar dificuldades no processo de aprendizagem da operação.

Palavras-chave: Transposição Didática Interna. Divisão de Números Naturais. Prática Docente.

Abstract: This article is an excerpt from an academic master's research that adopts the notion of didactic transposition by Yves Chevallard and aims to analyze aspects related to the internal didactic transposition process of the natural numbers division operation in elementary school. To support the analysis of the mathematics classes of three teachers, a study of the legal documents of Brazil and the State of Pernambuco was carried out, thus being analysis of textbooks for the 4th, 5th and 6th years and interviews with the teachers who work in those school years. Within the classes, the focus of analysis was the different meanings of the division, the calculation procedures, the treatment given to the rest and the interpretation of the results obtained, addressed or not into the observed classes. When comparing the knowledge expected to be taught and the knowledge effectively taught,

José André Bezerra da Cruz Mestre em Educação Matemática e Tecnológica. Professor do Colégio Municipal Gerson de Albuquerque Maranhão e da Escola João Rodrigues Cardoso, em Águas Belas. Pernambuco, Brasil.

iD orcid.org/0000-0002-0132-7238

$\bowtie$ andrebezerra25@hotmail.com

Rosinalda Aurora de Melo Teles Doutora em Educação. Professora do Programa de Pós-Graduação em Educação Matemática e Tecnológica da Universidade Federal de Pernambuco (UFPE). Pernambuco, Brasil.

iD orcid.org/0000-0002-7289-3501

$\bowtie$ rosinaldateles@yahoo.com.br

Recebido em 28/05/2020 Aceito em 30/06/2020 Publicado em 29/07/2020 changes, deformations and gaps were found, which could cause difficulties in the process of learning the operation.

Keywords: Internal Didactic Transposition. Division of Natural Numbers. Teaching Practice.

\section{Introdução}

Pesquisas acadêmicas em Educação Matemática abordam a existência de certa distinção entre o saber que é previsto para ser ensinado e o que é realmente ensinado nas salas de aula 
(JOSSE, 1992; MENEZES, 2004; MATOS FILHO, MENEZES, SILVA e QUEIROZ, 2008). Estas pesquisas mostram que 0 saber a ser ensinado sofre transformações até se tornar saber efetivamente ensinado.

Esse processo de transformação dos saberes é o que Yves Chevallard denomina de transposição didática, e refere-se às modificações que são feitas nos conteúdos dos programas e manuais de ensino. Assim, Bordet (1997) sugere a existência de duas fases nessa teoria de Chevallard: a transposição didática externa, que é a passagem do saber científico, denominado de saber sábio para o saber a ensinar; e a transposição didática interna caracterizada pela passagem do saber a ensinar ao saber efetivamente ensinado em sala de aula.

Nesse artigo nos interessamos pelo processo de transposição didática interna da operação divisão. Vale destacar que as aprendizagens da operação divisão muitas vezes não têm sido garantidas a maioria dos alunos que chegam aos Anos Finais do Ensino Fundamental e Ensino Médio, pois muitos alunos ainda apresentam dificuldades para a realização dos cálculos numéricos, seja mobilizando algoritmos pessoais ou o algoritmo euclidiano convencional, bem como dificuldades relacionadas aos diferentes significados da divisão — partição e quotição —, ao tratamento dado ao resto e à interpretação dos resultados obtidos. Notadamente destacam-se muitas incompreensões relacionadas à divisão, conforme evidenciaram Saiz (2001), Benvenutti (2008) e Alves (2012).

Além disso, o ensino da operação de divisão, em grande parte das salas de aula, ainda é realizado por meio de uma abordagem que prioriza um ensino sem grandes reflexões. Souza (2010, p. 2), afirma que "as operações são apresentadas como técnicas, procedimentos e ações que, quando aplicadas em sequência e repetidamente, conduzem à resposta". Dessa maneira os alunos aprendem muitas vezes apenas técnicas não compreendendo os processos envolvidos para chegar em tal resposta.

Em contraposição à essa forma de abordagem, os Parâmetros Curriculares Nacionais de Matemática (BRASIL, 1997, p. 39) recomenda que o trabalho com as operações no Ensino Fundamental deve se concentrar "na compreensão dos diferentes significados de cada uma delas, nas relações existentes entre elas e no estudo reflexivo do cálculo, contemplando diferentes tipos - exato e aproximado, mental e escrito".

Partindo dessas compreensões iniciais, o presente artigo é um recorte de uma pesquisa de mestrado que buscou investigar como a transposição didática interna ocorre no ensino da 
operação divisão de números naturais no $4^{\circ}, 5^{\circ}$ e $6^{\circ}$ anos do ensino fundamental. Tal estudo teve como foco de análise a divisão de números naturais de forma geral, ou seja, os diferentes procedimentos de cálculo - mental, escrito, exato, aproximado, por estimativas, arredondamentos e utilizando os algoritmos convencionais -, os significados partição e quotição da divisão, bem como o tratamento dado ao resto e à interpretação dos resultados obtidos. Especificamente neste artigo analisamos, a partir de observações em sala de aula, os principais aspectos relacionados ao processo de transposição didática interna da operação divisão de números naturais em aulas de Matemática ministradas no Ensino Fundamental por três professores.

Do ponto de vista teórico, baseamo-nos na noção proposta por Yves Chevallard sobre a transposição didática, buscando identificar e analisar as transformações realizadas pelo professor em relação ao saber a ensinar, no que se refere à operação divisão de números naturais.

\section{A transposição didática de Yves Chevallard}

Dentre os muitos estudos que já adotaram como aporte teórico a transposição didática (TD), Rosa dos Santos (2015) aponta que a TD apresenta um elemento importante em sua composição que é a relação recíproca entre saber e instituição - a palavra instituição é utilizada em conformidade com a Teoria da Transposição Didática, ou seja, num sentido mais amplo do que na vida cotidiana. A noção de saber pode ser compreendida como formas de organização de conhecimentos, ou seja, fruto da ação humana institucional. Chevallard (1991) aponta que todo saber é saber de uma instituição, bem como um mesmo saber pode viver em instituições diferentes. Na presente pesquisa levaremos em consideração o estudo da operação divisão de números naturais, que transita por diversas instituições como a escola, uma disciplina, a sala de aula etc. Segundo Chevallard (1991), para que um saber possa fazer parte de uma instituição, é necessário que o mesmo se sujeite a certas exigências, o que acarreta a necessidade dele, ou seja, é necessário se transformar, caso contrário não poderá pertencer à instituição. $O$ fenômeno da transposição didática, proposto por Chevallard (1991) é definido como o conjunto de transformações adaptativas que um objeto de saber a ensinar sofre até se tornar objeto de ensino. Conforme defende 0 autor,

um conteúdo do conhecimento, tendo sido designado como saber a ensinar sofre então um conjunto de transformações adaptativas que vão torná-lo apto a tomar lugar entre os "objetos de ensino". O "trabalho" que, de um objeto de saber a ensinar faz um objeto de ensino, é chamado de transposição didática (CHEVALLARD, 1991, p, 39). 
Chevallard (1991) evidencia, em sua teoria, a noção de habitat de um objeto como sendo o tipo de instituição onde se encontra o saber relacionado ao objeto de estudo, que por sua vez determinará seu nicho, ou seja, a função desse saber. Dessa maneira, o autor distingue as instituições como produtoras, utilitárias, transpositivas e de ensino.

As instituições produtoras, segundo Rosa dos Santos (2015, p. 27), "são, geralmente, as mais valorizadas pela sociedade e formadas por cientistas, intelectuais e pesquisadores"; as utilitárias (empresas, indústrias, comércios etc.) "são aquelas que utilizam o conhecimento produzido nas instituições produtoras" (p. 28); as transpositivas (a noosfera) "são consideradas a mola maestra da transposição didática, pois permitem que os saberes passem de uma instituição a outra" (p. 28); e as instituições de ensino (escolas) "são as mais visíveis culturalmente e representadas pelo professor em sala de aula" (p. 28).

Para Chevallard (1991), a noosfera é uma instituição pensante e invisível, que tem como responsabilidade selecionar os saberes sábios que farão parte do currículo escolar. Os sujeitos que fazem parte da noosfera são: especialistas, técnicos, gestores, secretários educacionais etc., são os responsáveis pela elaboração das diretrizes curriculares, ou seja, normatizam o que deve ser estudado nas instituições de ensino.

Nesse sentido, Chevallard (1991) aponta o processo de transformações dos saberes em três grupos: savoir salvant (saber sábio), savoir à enseigner (o saber a ensinar) e o savoir enseigné (saber ensinado). Cada um desses grupos tem seus próprios sujeitos, suas próprias instituições, seus objetivos e normas que influenciam nas transformações ocorridas no saber. Tais normas configuram um processo de preparação didática, que podem ser resumidas, de acordo com Chevallard (1991), como a dessincretização, a despersonalização, a programabilidade, a publicidade do saber e o controle social das aprendizagens.

A dessincretização, segundo Rosa dos Santos (2015, p. 30), "consiste na exigência de conduzir primeiramente uma divisão da teoria entre áreas e especialidades bem delimitadas, em que cada uma será expressa por meio de um discurso próprio". Na despersonalização há uma exigência que consiste em separar do saber qualquer contexto pessoal, ou seja, é retirada toda e qualquer conexão com o ambiente onde ele foi gerado. Segundo Chevallard (1991),

o saber que produz a transposição didática será, então, um saber exilado de suas origens, e separado de sua produção histórica na esfera do saber científico, legitimando-se, então, o saber ensinado como algo que não é de tempo algum nem de lugar algum, e não se legitimando mediante o recuso à autoridade de um produtor, 
A programabilidade da aquisição do saber incide na determinação de uma programação da aprendizagem, de maneira sequencial e racional. Já na publicidade, a exigência define explicitamente 0 que deve ser ensinado. A linguagem utilizada nessa nova divulgação é nova e muitos termos usados no saber sábio são omitidos.

Por fim, a última exigência é o controle social das aprendizagens, que segundo Rosa dos Santos $(2015$, p. 31) "está intimamente relacionado com a programabilidade, que é chamada de publicidade, pois determina quais os saberes que deverão ser ensinados, para que faixa etária, em que tempo, como ensiná-los (muitas vezes) e o que avaliar".

Como resultado destes processos, Rosa dos Santos (2015) evidencia que o saber a ensinar toma forma de conteúdo didático sendo apresentado em diversos documentos, segundo uma amostra racional e uma organização progressiva, linear e cumulativa, devendo estar acessíveis aos professores. Segundo Henry (1991), dá-se início a uma nova transformação, dando origem ao saber escolar (savoir scolaire). Tal saber está entre o saber a ensinar e o saber ensinado, isto é, são os livros didáticos e manuais de ensino que auxiliam o professor na preparação de suas aulas e são produzidos a partir dos documentos que os norteiam.

Outra transformação do saber que está entre o saber a ensinar e o saber ensinado, foi denominada por Ravel (2003) de saber preparado (savoir apprêté). Esse saber decorre das escolhas didáticas e matemáticas realizadas pelo professor ao lecionar um dado assunto matemático (saber matemático), pois durante o planejamento da aula a ser dada o professor faz suas escolhas, utiliza o livro didático adotado pela escola ou mesmo outros materiais de sua preferência, ou seja, decide sobre a forma de organização e exposição dos saberes.

Todavia, esse saber preparado pelo professor, algumas vezes registrado em seu plano de ensino - tendo em vista que várias pesquisas e também observações empíricas apontam que a maioria dos professores não faz um planejamento sistemático, por escrito, das aulas que ministra —, poderá ou não corresponder àquele efetivamente vivenciado em sua sala de aula, conforme analisados por pesquisas como a de Brito Menezes (2006) e Bessa de Menezes (2004).

Nessa etapa da transposição didática, o professor transforma o saber preparado em saber ensinado. Contudo, Rosa dos Santos (2015) destaca que "essa transposição é influenciada tanto pela concepção de educação do professor, dos coordenadores de área, dos supervisores e dos 
familiares quanto pelas condições e impedimentos existentes na instituição escolar (tipo de escola, localização, metas, projeto político pedagógico, etc.)" (p. 33).

Chevallard (1991) destaca ainda que as transformações podem acontecer de duas maneiras distintas, são elas: transposição didática stricto sensu e transposição didática lato sensu. A primeira ocorre quando a evolução das ideias é analisada em relação a um dado conceito, enquanto a segunda ocorre quando a análise é realizada em um contexto mais amplo. Segundo o autor, as transformações também podem ser externas (transformações do saber sábio em saber a ensinar) e internas (transformações do saber a ensinar em saber efetivamente ensinado).

\section{A transposição didática externa}

O fenômeno da transposição didática tem como etapa inicial a transposição didática externa, que consiste na transformação do saber científico ou saber sábio, conforme denomina o próprio Chevallard (1991), em saber a ensinar. Esse processo de transformação é realizado em um espaço denominado noosfera, que envolve pessoas e instituições responsáveis por designar o que deve ser ensinado nas instituições de ensino. Conforme afirma Bessa de Menezes (2004),

podemos, nesse sentido, referirmo-nos aos didatas, professores, pedagogos, técnicos de instituições do Governo responsáveis por gerir o ensino (no caso do Brasil, o MEC, por exemplo). Enfim, pessoas (muitas delas representando instituições) que vão elaborar programas, diretrizes curriculares, livros didáticos, etc. os quais aparecem, então, como instrumentos reguladores, no sentido de que eles vão normatizar o que deve ser ensinado na escola, o saber a ensinar, consolidando uma primeira etapa da transposição didática e caracterizando a transposição didática externa. (p. 22).

Ao longo do processo de transformação dos saberes, o saber científico sofre deformações, adaptações e modificações, deixando partes de seu formato original. Dessa maneira é necessário que se realize o que Chevallard (1991) intitulou de vigilância epistemológica para que o saber a ensinar não se desconecte do saber científico, de forma a acarretar obstáculos à aprendizagem. Dialogando também sobre o tema, Araújo (2009) aponta que essa vigilância é o principal objetivo da transposição didática, uma vez que visa analisar o saber do instante da sua produção (saber sábio) até ser ensinado nas salas de aula (saber ensinado). Nessa perspectiva, Rosa dos Santos (2015) destaca que

para que o saber em jogo tenha sentido e ajude na compreensão do estudante é necessário que o professor faça o caminho contrário do cientista (matemático), ou seja, contextualize o conceito. Para isso é necessário promover situações que levem 0 
estudante a agir, formular e testar hipóteses, legitimar e, por fim, o educador descontextualiza para poder institucionalizar, para que haja uma generalização (p. 32).

Uma das formas de realizar essa contextualização em sala de aula é colocar para os alunos situações semelhantes àquelas que deram origem a esse dado saber, ou seja, colocar eles na posição do cientista (matemático).

Devido às deformações e adaptações que o saber científico sofre ao longo do processo da transposição didática, o professor quase nunca terá acesso ao saber original, mas sim a adaptações por meio dos livros didáticos e/ou manuais de ensino, sendo ainda responsável por mais uma etapa da transposição didática que ocorrerá no seio da sala de aula (transposição didática interna).

Essas sucessivas adaptações do saber fazem surgir outro elemento que Chevallard (1991) chamou de criações didáticas, que são artifícios utilizados com intuito de facilitar a apropriação do conhecimento por parte dos alunos - um exemplo bastante conhecido é o diagrama de Venn, utilizado para facilitar o processo de ensino e aprendizagem da Teoria dos Conjuntos. Contudo, essas criações didáticas trabalhadas em sala de aula podem acarretar diferenças com relação ao saber a ensinar, como exemplo, ensinar o diagrama de Venn pensando que desta maneira ensina-se Teoria dos Conjuntos.

Ainda sobre as criações didáticas, Rosa dos Santos (2015, p. 33), evidencia que "algumas definições e propriedades geralmente são ditas de forma diferente e algumas demonstrações sofrem modificações para que os alunos compreendam". Tudo isso visa facilitar o processo de ensino e aprendizagem, isto é, adaptar os saberes às condições cognitivas e sociais dos alunos.

Chevallard (1991) recomenda que o saber ensinado não deve ser tão próximo nem tão distante do saber sábio. Nesse caso, há a necessidade de equilibrio entre o saber sábio e o saber ensinado, com vista que um (saber ensinado) não se desconectar do outro (saber sábio).

Dando continuidade ao processo de transposição didática, essa chega à sala de aula consolidando a última etapa deste processo.

\section{A transposição didática interna}

Neste artigo nos interessamos pela transposição didática interna da operação divisão de números naturais no Ensino Fundamental. 
A transposição didática interna é a última transformação sofrida pelo saber sábio, tendo enquanto parceiros envolvidos, o professor e os alunos. Tal transformação é decorrente da abordagem do professor em relação aos saberes a ensinar. De acordo com Brito Menezes (2006), na sala de aula o professor não traduz fielmente o que o livro didático traz, mas sim ele fornece uma nova abordagem a esse saber, de forma a transformá-lo, modificá-lo, criando, conforme Chevallard (1991), um metatexto, ou seja, um texto do texto.

Brito Menezes (2006) declara que na relação professor/aluno/saber (relação didática), 0 professor quase nunca terá acesso ao saber original, mas sim as adaptações/deformações por meio dos livros didáticos e manuais de ensino, sendo ele, ainda o responsável por mais uma etapa nessa adaptação que ocorrerá no interior da sala de aula, denominada de transposição didática interna.

Dessa maneira, a transposição didática interna é realizada pelo professor de forma que, ele mesmo, não percebe que está realizando tal feito, conforme defende Chevallard (1991). Bessa de Menezes (2004), também dialogando sobre o tema, afirma que a transposição didática interna acontece de maneira inconsciente para o professor, ou seja, ele pensa que está sendo fiel ao saber a ensinar.

É importante abordar que, apesar do professor realizar tal processo de maneira inconsciente, ele faz planejamentos para suas aulas, organiza materiais de estudo, buscando uma melhor forma de ensinar os assuntos para seus alunos. Dessa forma, podemos dizer que a transposição didática interna envolve elementos conscientes e inconscientes.

Bessa de Menezes (2004) defende que a transposição didática interna está vinculada fundamentalmente aos elementos aluno e saber, que juntamente com o professor compõem o sistema didático. Este sistema é instituído a partir das relações aluno/professor, aluno/saberes e professor/saberes. Tratando-se da relação professor/saberes, esta detém uma forte interligação com a transposição didática interna, uma vez que a transformação do saber a ensinar em saber ensinado transcorre da relação que o professor detém com o saber a ensinar.

Tais pesquisas, possivelmente, confirmem a existência da transposição didática interna, proposta por Chevallard (1991), o que nos leva à reflexão sobre quais os principais aspectos relacionados ao processo de transposição didática interna da operação divisão de números naturais no Ensino Fundamental levando em consideração as análises das aulas dos professores participantes desta pesquisa. 
Nesse estudo optamos pela discussão dos diferentes significados da divisão, os procedimentos de cálculo da divisão, o tratamento dado ao resto e a interpretação dos resultados obtidos na operação divisão, uma vez que representam para transposição didática saberes a serem mobilizados pelos professores, ou seja, saberes a ensinar.

\section{Os diferentes significados da divisão}

A análise do processo de desenvolvimento e uso significativo dos conceitos da divisão de números inteiros fundamenta-se na Teoria dos Campos Conceituais, desenvolvida pelo psicólogo francês Gerard Vergnaud (1996), mais especificamente, no campo conceitual das estruturas multiplicativas. Neste estudo, no entanto, fizemos um recorte com o olhar da Teoria da Transposição Didática, construindo nossa discussão a partir dos tipos de problemas (SELVA, 1998); procedimentos de cálculo; tratamento dado ao resto na divisão e interpretação dos resultados obtidos na operação apenas no domínio dos números naturais.

Selva (1998) aborda em seu trabalho que na operação divisão são encontrados dois tipos de problemas básicos: os problemas de partição e os de quotição. Nos problemas de partição, "conhece-se o número total de elementos em um conjunto, que deverá ser distribuído igualmente em um número de partes predeterminado, devendo-se calcular o número de elementos em cada parte" (SELVA, 1998, p. 97); já nos problemas de quotição, "o conjunto conhecido deve ser dividido em partes de grandeza previamente estabelecida, devendo-se calcular o número de partes que serão obtidas" (p. 97).

Como forma de esclarecer esses dois tipos de problemas que exploraram os significados partição e quotição da operação divisão, bem como mostrar a diferença entre os dois tipos, Selva (1998) apresenta os seguintes exemplos:

\footnotetext{
Partição - "D. Maria fez 15 doces para dividir igualmente entre três bandejas. Quantos doces serão colocados em cada bandeja?"

Quotição - "D. Maria fez 15 doces e quer arrumar esses doces colocando três doces em cada bandeja. De quantas bandejas ela vai precisar?" (SELVA, 1998, p. 97).
}

A autora ainda explica que no exemplo do problema de partição conhece-se o número de doces e o número de bandejas, devendo-se calcular a quantidade de doces por bandeja, já no problema de quotição tem-se a quantidade total de doces e a quantidade de doces por bandeja, devendo-se calcular a quantidade de bandejas. É importante frisar que apesar desses problemas 
serem diferentes do ponto de vista das quantidades conhecidas, os mesmos podem ser resolvidos pelo mesmo cálculo numérico, nesse caso, $15 \div 3$.

Selva (1998) buscou investigar o efeito do uso de materiais na resolução de problemas de divisão, bem como determinar se os dois tipos de problemas de divisão, de partição e de quotição, leva a diferentes formas de utilização do material e a diferenças no número de acertos e erros entre crianças que receberam e que ainda não receberam ensino formal sobre divisão. Entre seus resultados verificou que o desempenho das crianças nos problemas de partição (79,4 de acertos) e quotição (78,96 de acertos) foi semelhante. Assim, esses resultados não apoiam os estudos que apontam o modelo de partição como sendo compreendido mais cedo do que o modelo de quotição.

\section{Os procedimentos de cálculos da divisão}

Desde os Parâmetros Curriculares Nacionais (BRASIL, 1997, 1998) defendia-se que 0 ensino da divisão deve contemplar os diferentes procedimentos de cálculo — estratégias pessoais, cálculos mental, escrito, exato, aproximado e técnicas convencionais (algoritmos). Os Parâmetros para Educação Básica do Estado de Pernambuco (PERNAMBUCO, 2012) destacam o cálculo mental, estimativas, arredondamentos e algoritmos convencionais. Já a Base Nacional Comum Curricular (BRASIL, 2017) recomenda o cálculo mental, estimativas e algoritmos convencionais. Pelo que se pode observar, esses documentos concordam entre si.

Selva (1998) aponta cinco categorias de estratégias evidenciadas em sua pesquisa para resolução de problemas de divisão: 1) representação direta com distribuição de pequenas quantidades; 2) representação direta com formação de grupos; 3) ensaio e erro; 4) repetição aditiva; e 5) uso de fato conhecido.

Como forma de melhor compreender cada uma das estratégias citadas anteriormente, vejamos a explicação de cada uma delas: a estratégia 1, representação direta do problema com distribuição de pequenas quantidades, leva em consideração a correspondência um a um ou a separação dos elementos em grupos de dois ou três para resolver um problema proposto; a 2 , representação direta com formação de grupos, foi evidenciada quando as crianças participantes da pesquisa contavam fichas ou desenhavam marcas em número correspondente ao valor do dividendo e formavam ou circulavam grupos com quantidade indicada pelo valor do divisor, por fim contavam o número de grupos obtidos; a 3, ensaio e erro, consiste em escolher sucessivas vezes um certo número de elementos para constituir cada grupo, contando a cada escolha 0 
número total de elementos, com vista a determinar se atingiu a quantidade expressa pelo dividendo do problema; a estratégia 4, denominada de repetição aditiva, considera tanto os casos que o problema é resolvido por adições sucessivas da mesma quantidade, como também aqueles que são resolvidos por subtração sucessiva da mesma quantidade; e 5, uso de fato conhecido, consisti na utilização de fatos conhecidos, podendo envolver multiplicações ou divisões.

Diante disso, percebemos que são várias as estratégias de cálculos utilizadas pelos estudantes. Contudo, defendemos primeiramente um bom trabalho com as estratégias pessoais, ou seja, os procedimentos próprios dos alunos, para depois haver a formalização ou mesmo ensino dos procedimentos convencionais em sala de aula. Conforme afirma Saiz (2001, p. 188), "temos que permitir que as crianças comprovem seus próprios procedimentos, suas próprias soluções, antes de conhecer os algoritmos tradicionais".

\section{0 tratamento dado ao resto}

A divisão é uma operação matemática que ocorre entre dois operandos, dizemos que existe um dividendo e um divisor, que irão produzir um quociente inteiro e resto inteiro como resultado. A operação obedece à propriedade fundamental: DIVIDENDO (D) = QUOCIENTE (q) $\times$ DIVISOR (d) × RESTO (r). Quando o resto é igual a zero dizemos que a divisão é exata, mas nem sempre é possível realizar a divisão exata no conjunto dos números naturais, daí então a divisão inexata ou com resto diferente de zero. Vários estudos já refletiram sobre o tratamento dado ao resto numa divisão com números naturais. Selva (1998), por exemplo, constatou que as crianças obtiveram melhor desempenho nos problemas de divisão exata, isto é, as crianças apresentaram mais dificuldades nos problemas com resto. Essas dificuldades estão relacionadas ao tratamento dado ao resto na divisão. Assim, a autora observou seis estratégias para lidar com o resto: a) solicitar maior quantidade; b) aceitar uma desigualdade, ou seja, aceitar que um dos grupos ficasse com mais; c) remover o resto; d) formar grupos iguais, independentemente do enunciado do problema; e) refazer o problema; e f) dividir o resto em partes que pudessem ser distribuídas entre todos os grupos.

Foi evidenciado também um maior uso da aceitação de desigualdade entre as crianças mais jovens — da alfabetização e da primeira série, atual segundo ano —, fato que pode ser explicado pela dificuldade que apresentaram ao lidar com o resto. Para elas, resolver problema de divisão parece que significa dividir o total de elementos especificado (o dividendo) sem deixar 
nenhuma sobra. Já na segunda série (atual terceiro ano) pôde-se verificar um aumento da divisão do resto e o decréscimo da aceitação de desigualdades. Dessa maneira, as crianças da segunda série mostraram que as regras contidas no enunciado da questão não podiam ser burladas, não se podendo admitir modificações no valor do dividendo e no divisor, além dos grupos formados terem que apresentar igual quantidade, mesmo que sobrassem elementos.

Selva, Borba e Steedman (2004) investigaram o efeito dos significados dados à divisão e de representações simbólicas na resolução de problemas de divisão com resto na busca de observar até que ponto eles afetam o desempenho das crianças. Em relação ao uso de estratégias no tratamento do resto, não foram observadas diferenças nos tipos de estratégias em função do resto (grande ou pequeno) nas séries investigadas ( $2^{\mathrm{a}}$ e $3^{\mathrm{a}}$ séries, atuais $3^{\circ}$ e $4^{\circ}$ anos), ou seja, 0 fato de o resto ser um número mais próximo do divisor ou ser menor parece não ter influenciado a escolha das estratégias de tratamento dado ao resto. Essa forma de tratamento foi influenciada apenas pelo tipo de problema (partição ou quotição). As principais estratégias usadas pelos sujeitos participantes foram: subdividir o resto em partes suficientes para a nova redistribuição, acrescentar ao quociente, dar um novo fim ao resto e ignorar o resto.

Borba e Selva (2006) analisaram a influência de significados dados à divisão e de representação simbólicas na resolução de problemas de divisão com resto diferente de zero. Com relação ao tratamento dado ao resto, as autoras chamam a atenção para as dificuldades evidenciadas pelos dois grupos participantes do estudo (alunos da $3^{\mathrm{a}}$ e $5^{\mathrm{a}}$ séries, atuais $4^{\circ}$ e $6^{\circ}$ anos). Sugerem que o uso de representações variadas, um estudo significativo do número racional, um trabalho com resolução de problemas e o retorno ao enunciado do problema após a resolução possam ser caminhos para ajudar os alunos na compreensão do tratamento dado ao resto em problemas de divisão. Dessa maneira, notamos que o resto em uma divisão gera muita dificuldade por parte dos alunos, e o correto tratamento dado ao mesmo depende dos conhecimentos utilizados.

\section{A interpretação dos resultados obtidos na operação divisão}

Um dos aspectos importantes sobre a interpretação dos resultados obtidos na divisão é o questionamento: o cálculo numérico foi realizado e agora qual a resposta do problema? $\mathrm{Na}$ resolução de problemas de divisão o quociente nem sempre é a resposta. Ou seja, ao realizar o cálculo da divisão de um dado problema matemático, ao término necessitamos interpretar os 
resultados obtidos na operação, pois dependendo do problema o quociente, o resto, o quociente mais um e o resto mais uma quantidade podem ser as soluções do problema como ilustrado a seguir com alguns exemplos.

- Exemplo 1: A resposta é o quociente - Paulo quer dividir 28 pirulitos entre seus quatro sobrinhos. Quantos pirulitos irá receber cada um?

- Exemplo 2: A resposta é o quociente mais um - Um ônibus de uma empresa de turismo transporta 45 pessoas. Quantos ônibus são necessários, no mínimo, para transportar 182 pessoas?

- Exemplo 3: A resposta é o resto - Quantas semanas completas há em 130 dias? Quantos dias sobram?

- Exemplo 4: A resposta é o resto mais uma quantidade - João em sua plantação utiliza 30 sementes para plantar em cada canteiro. Sabendo que ele dispõe de 122 sementes. Quantos canteiros ele vai utilizar? E para completar todos os canteiros utilizados, João irá precisar de mais quantas sementes?

No exemplo 1, a resposta do problema é 7 pirulitos, ou seja, a resposta é o quociente (sete) da divisão de 28 por 4 . Já no exemplo 2, a resposta é 5 ônibus (o quociente 4 mais 1), isto é 4 (ônibus com 45 pessoas) + 1 (um ônibus para as duas pessoas que sobrarão). No exemplo 3 , a resposta da segunda pergunta é o resto da divisão de 130 por 7, ou seja, 4 (dias). E por fim, a resposta da segunda pergunta do exemplo 4, é o resto da divisão 122 por 30 somado com 28, ou seja, $2+28$. Esses exemplos reforçam a importância de os alunos saberem interpretar os resultados obtidos nos seus cálculos, com o objetivo de saber qual a resposta de um dado problema.

\section{Procedimentos metodológicos}

Para alcançar os objetivos traçados, tivemos como foco de análise o saber previsto e 0 saber efetivamente ensinado de professores do $4^{\circ}, 5^{\circ}$ e $6^{\circ}$ anos, isto é, professores pedagogos e licenciados em Matemática, acompanhando todo o processo de ensino da operação divisão de uma instituição de ensino da rede municipal da cidade Águas Belas (PE), localizada no Agreste Meridional. A rede de ensino atualmente é composta por 33 escolas e 9.418 alunos. Nosso estudo foi realizado com uma amostra deste universo: três professores de uma escola da zona urbana. 0 
intuito, entre outros aspectos, foi valorizar a pesquisa no interior do Agreste Meridional e, também, colocar em evidência a Educação Matemática nesta região. Além disso, esse estudo se insere no âmbito das pesquisas realizadas pelo Grupo de Pesquisa SEMEAR.

De modo mais amplo, o procedimento metodológico utilizado no estudo a nível de mestrado constou das seguintes etapas: estudo de documentos legais para orientação curricular do Brasil e do Estado de Pernambuco; análise dos livros didáticos adotados pelos professores participantes da pesquisa; entrevistas; e observação e análise das aulas dos três professores participantes da pesquisa. Neste recorte, nos deteremos nos resultados obtidos na análise das aulas dos três professores.

O objetivo da primeira etapa da metodologia foi, além de identificar as orientações, elaborar um roteiro com os principais aspectos relacionados ao ensino da divisão contidos nos documentos analisados que foram levados em consideração na observação das aulas dos professores participantes da pesquisa. Tal roteiro é composto pelos diferentes procedimentos de cálculos (mental, escrito, exato, aproximado, por estimativas, arredondamentos e utilizando os algoritmos convencionais); os significados da divisão (partição e quotição); o tratamento dado ao resto; e a interpretação dos resultados obtidos. Vale reforçar que os documentos de orientação curricular representam para a transposição didática interna o saber a ser ensinado, ou seja, 0 saber previsto para ser ensinado nas salas de aulas.

\subsection{Estudo de documentos legais do Brasil e do Estado de Pernambuco}

Ao analisarmos nos documentos legais do Brasil e do estado de Pernambuco, dentre eles os Parâmetros Curriculares Nacionais de Matemática - PCN (BRASIL, 1997, 1998), a Base Curricular Comum para as Redes Públicas de Ensino de Pernambuco (2008), Parâmetros para a Educação Básica do Estado de Pernambuco (2012) e a Base Nacional Comum Curricular (2017), quais são as orientações para a efetivação do ensino da operação divisão de números naturais durante o Ensino Fundamental, ou seja, do $2^{\circ}$ ao $9^{\circ}$ ano, os principais resultados obtidos nessa etapa foram observar que os procedimentos de cálculos defendidos são: mental, escrito, exato, aproximado, por estimativas, arredondamentos e utilizando os algoritmos convencionais. Os

\footnotetext{
1 SEMEAR: Subsidiar o Ensino de Ciências e a Educação Matemática no Agreste Pernambucano Efetuando Aprofundadas Reflexões - Grupo de Pesquisa certificado pelo CNPq e liderado pela Profa. Dra. Rosinalda Aurora de Melo Teles.
} 
significados da divisão a serem explorados durante o processo de ensino da operação divisão de número naturais são, principalmente, partição e quotição.

É importante destacar ainda os aspectos convergentes e divergentes encontrados nos documentos analisados. Como aspectos convergentes, início do ensino da operação de divisão a partir do $3^{\circ}$ ano e utilização dos seguintes procedimentos de cálculo: mental, estimativas e algoritmos convencionais. Já nos aspectos divergentes, encontramos em relação aos significados da operação divisão, pois há documentos que apontam outros significados além de partição e quotição, como exemplos: proporcionalidade (PERNAMBUCO, 2008, 2012) e medida (BRASIL, 2017). Outro aspecto divergente se relaciona aos procedimentos de cálculos, uma vez que, há documentos que destacam mais estratégias de cálculos que outros. Nesse sentido, as divergências podem ser vistas como aspectos que se complementam nos documentos analisados.

\subsection{Análise dos livros didáticos adotados nos $4^{\circ}, 5^{\circ}$ e $6^{\circ}$ anos e usados pelos professores participantes da pesquisa}

O objetivo da análise dos livros didáticos foi buscar compreender o que a escola e os professores estabelecem enquanto saber a ensinar, considerando que este tem se mostrado como uma espécie de "texto do saber", conforme conceitua Chevallard, bem como verificar como a operação divisão é apresentada para ser ensinada em sala de aula, uma vez que os livros didáticos são considerados para a transposição didática o saber a ser ensinado. Tal análise enfatizou a abordagem dos conceitos e atividades relativas ao ensino da operação divisão em três livros didáticos, para $04^{\circ}, 5^{\circ}$ e $6^{\circ}$ anos do Ensino Fundamental. Vale destacar também que para analisar o capítulo ou unidade específica de cada livro que visava ensinar a operação divisão de números naturais, utilizamos as categorias propostas na presente pesquisa: os diferentes procedimentos de cálculo (mental, escrito, exato, aproximado, por estimativas, arredondamentos e os algoritmos convencionais); os significados da divisão (partição e quotição); o tratamento dado ao resto; e a interpretação dos resultados obtidos.

É importante frisar ainda que a escolha dos livros didáticos se deu por serem esses que os professores afirmaram utilizar em suas aulas, na realização da entrevista.

Os resultados apontaram que os três livros analisados destacam o trabalho com os significados da divisão partição e quotição; 0 ensino de divisões exatas e não exatas; e o trabalho com questões em que a solução da divisão é o quociente. Em se tratando dos aspectos 
divergentes observamos que: o significado partição foi mais presente nas questões analisadas no $4^{\circ}$ e $6^{\circ}$ anos com respectivamente $46,3 \%$ e $61,11 \%$ das questões, enquanto no $5^{\circ}$ ano 0 significado que prevaleceu foi quotição com $41,18 \%$ das questões; a quantidade de procedimentos de cálculos apresentados nos livros diminui no decorrer dos anos observados, ou seja, no $4^{\circ}$ ano, por exemplo, são exploradas as estratégias pessoais, cálculo mental, estimativas, arredondamentos, os algoritmos euclidiano (pelo processo longo) e americano; já no $6^{\circ}$ ano são explorados apenas 0 arredondamento e o algoritmo euclidiano (pelo processo longo); apenas no $4^{\circ}$ ano é trabalhado divisões em que solução é o quociente mais um; no $5^{\circ}$ é trabalhado somente questões em que a solução é o quociente; e no $4^{\circ}$ e $5^{\circ}$ anos são trabalhados também questões em que solução é o resto.

É importante comentar que a prevalência do significado partição nos livros didáticos, bem como a redução dos procedimentos de cálculos ao longo dos anos podem acarretar prejuízos para a aprendizagem dos alunos, uma vez que o ensino da operação divisão de números naturais acaba por ficar centrado em uma visão limitada.

Vale frisar ainda o pouco trabalho com divisões não exatas no $5^{\circ}$ ano, aparecendo apenas em uma das dezessete questões encontradas na análise da unidade do livro, fato esse que pode acarretar dificuldades nos alunos nas operações de divisão que tenham resto. Dessa maneira, se faz necessário que o professor que for utilizar esse livro leve para suas aulas mais questões de divisões não exatas, como forma de sanar essa fragilidade apresentada na unidade do livro analisado.

Outro ponto importante é uso da calculadora no livro do $6^{\circ}$ ano, aspecto defendido nos PCN (BRASIL, 1997, 1998), na BCC (PERNAMBUCO, 2008) e nos PCPE (PERNAMBUCO, 2012). Dessa maneira, percebemos que o livro do $4^{\circ}$ ano é o que atende de forma mais satisfatória as orientações curriculares analisadas, pois aborda os principais procedimentos de cálculos, os significados da divisão partição e quotição; trabalha divisões exatas e não exatas, bem como traz questões em que a solução é o quociente, o quociente mais um e o resto.

\subsection{Entrevista}

Tendo em vista que pesquisas acadêmicas, e também observações empíricas, apontam que a maioria dos professores não faz um planejamento sistemático, por escrito, das aulas que ministra, a terceira etapa da pesquisa consistiu na realização de entrevistas com os professores 
participantes, com o objetivo de verificar quanto tempo esses professores acham que seria necessário para ensinar o conteúdo divisão de números naturais em suas turmas, bem como para sabermos o tempo necessário de observação do pesquisador na sala de aula de cada professor, além de fornecer dados sobre os livros didáticos e outros materiais utilizados em suas aulas de divisão de números naturais.

A partir da análise das entrevistas percebemos que para a primeira pergunta não há um tempo ideal, no ponto de vista dos professores pesquisados, para o ensino da divisão de números naturais, pois a definição desse tempo leva em consideração as particularidades de cada turma.

Com relação à segunda pergunta, definimos a partir das respostas dadas pelos professores, um tempo aproximado que levaríamos para observar as aulas de cada professor participante. Denominamos tempo aproximado, pois esse tempo pode variar conforme a necessidade do professor, totalizando um período aproximado de 37 dias de observação de aulas.

A partir da terceira pergunta identificamos os livros didáticos, ou seja, o saber escolar e os outros materiais utilizados pelos professores participantes da pesquisa para organizar suas aulas.

\subsection{Observação e análise das aulas dos três professores participantes da pesquisa}

Para finalização do estudo foi realizada a observação e a análise de aulas ministradas por um professor do $4^{\circ}$ ano, um do $5^{\circ}$ ano e um do $6^{\circ}$ ano. A escolha do $4^{\circ}, 5^{\circ}$ e $6^{\circ}$ anos levou em consideração que o processo de divisão começa a "realmente ser ensinado", de acordo com os documentos legais, a partir do $4^{\circ}$ ano do Ensino Fundamental - uma vez que no $3^{\circ}$ ano a exploração se restringe apenas às ideias iniciais -, bem como ao término do $6^{\circ}$ ano espera-se que tenha sido consolidado o ensino da divisão com números naturais, além da existência da transição dos Anos Iniciais para os Finais, que ocorre do $5^{\circ}$ para o $6^{\circ}$ ano.

Dessa maneira, observamos aulas ministradas por esses professores em situação de ensino da operação divisão. Para realizar a análise da prática docente, consideremos os seguintes critérios: saber a ensinar concretamente estabelecido pelos documentos legais $\mathrm{e}$ escola/professores por meio dos livros didáticos escolhidos e saber efetivamente ensinado pelos professores participantes da pesquisa; os diferentes procedimentos de cálculo (mental, escrito, exato, aproximado, por estimativas, arredondamentos e utilizando os algoritmos convencionais); 
os significados da divisão (partição e quotição); o tratamento dado ao resto; e a interpretação dos resultados obtidos priorizados pelo professor em sua transposição didática, visando uma posterior comparação com o saber a ser ensinado (documentos legais e livros didáticos).

\section{Análise e/ou resultados}

Como já anunciado, neste artigo apresentamos os dados obtidos na última etapa do estudo, ou seja, a observação e análise das aulas dos três professores participantes da pesquisa.

Como também já explicitado antes, com intuito de verificar o saber previsto para ser ensinado, analisamos documentos curriculares publicados pelo Ministério da Educação e pela Secretaria de Estado da Educação de Pernambuco, buscando averiguar as orientações para ensino da operação divisão. A partir delas definimos as categorias de análise para observação das aulas dos professores, como descrevemos anteriormente.

Ao observar e analisar as aulas, fazendo a comparação entre o saber previsto para ser ensinado (documentos legais analisados e livros didáticos) e o saber efetivamente ensinado (aulas dos professores), verificamos mudanças, deformações e lacunas no saber efetivamente ensinado em relação ao saber a ensinar. Essas se concentraram basicamente em:

- $4^{0}$ ano - uso de "regrinhas" com intuito de facilitar o processo de aquisição do conhecimento (criações didáticas); ausência de trabalho com as estimativas, os arredondamentos e o algoritmo americano (também conhecido como método das estimativas); pouco trabalho com o significado da divisão quotição; pouco ensino de questões em que a solução é o resto; e ausência de ensino de questões em que a solução é o quociente mais um.

- $5^{0}$ ano - uso de "regrinhas" com intuito de facilitar o processo de aquisição do conhecimento (criações didáticas); ausência de trabalho com os procedimentos de cálculos mental e o algoritmo americano; e pouco trabalho com o significado da divisão quotição.

- $6^{\circ}$ ano - uso de "regrinhas" com intuito de facilitar o processo de aquisição do conhecimento (criações didáticas); ausência de trabalho com o procedimento de cálculo arredondamento; prioridade do significado partição em suas aulas; e pouco trabalho com questões em que o resto é a solução da questão. 
Como forma de melhor evidenciar a observação das aulas dos professores participantes da pesquisa discutiremos, a seguir, as categorias propostas em cada ano de modo detalhado. Vale destacar que com o intuito de manter em anonimato a identidade de cada professor, os codificamos de P4, P5 e P6, em que P representa professor e a numeração 4, 5 e 6, o ano que cada professor ensina; bem como quando aparece LD no texto, esse significa livro didático.

\section{$\underline{4^{\circ} \text { ano do ensino fundamental }}$}

Os diferentes procedimentos de cálculo — os procedimentos de cálculos evidenciados nas aulas de P4 foram o trabalho com algoritmo euclidiano longo, o trabalho com estratégias pessoais e o cálculo mental - quando os próprios alunos pensavam em suas estratégias para realizar as divisões com os materiais disponibilizados por P4. Dessa maneira, podemos verificar, com relação ao saber a ensinar previsto nos documentos analisados e no livro didático adotado pela escola e que deveria ser utilizado por P4, a ausência de trabalho com as estimativas, os arredondamentos e o algoritmo americano (também conhecido como método das estimativas). Tais procedimentos de cálculos são previstos para ser ensinados nesse nível de escolaridade, $\left(4^{\circ}\right.$ ano. Assim, constatamos lacunas no saber efetivamente ensinado em relação ao saber previsto para ser ensinado com relação aos diferentes procedimentos de cálculo, haja vista o não ensino dos procedimentos já destacados.

Os significados da divisão - foram trabalhadas oito listas, num total de 38 questões, além de questões que eram trabalhadas durante a explicação do conteúdo, dentre as quais 36 foram de partição, 1 de quotição e 1 que se encaixa na categoria questões não contextualizadas — tais atividades estão relacionadas a questões não contextualizadas as quais exigem apenas efetuar a divisão.

Ao analisar tais dados percebemos uma predominância do significado partição com $94,74 \%$ das questões nas aulas de P4, enquanto as questões de quotição e não contextualizadas apenas com 2,63\% das questões cada. Dessa maneira, contatamos que P4 promove mudanças no saber a ensinar, isto é, o mesmo concentra-se praticamente no ensino do significado partição com $94,74 \%$ das questões trabalhadas, possivelmente por ter um maior conhecimento desse significado, pois de acordo com Câmara dos Santos (1997), a relação que o professor tem com o conhecimento matemático, justifica de certa maneira o professor avançar o tempo do saber de um dado objeto matemático - quando sua relação com tal saber falta intimidade - e frear esse tempo em outros objetos do saber — quando sua relação com tal saber é intima. Vale frisar, ainda, que 
P4 não utilizou o LD do $4^{\circ}$ ano nas aulas observadas, apenas atividades copiadas (xerox) ou escritas no quadro.

0 tratamento dado ao resto - verificamos que P4 explica inicialmente as divisões exatas e não exatas. Dessa forma, ensina o saber previsto para ser ensinado de modo coerente e adequado com os documentos. Vale destacar a ausência de tratamento dado ao resto na operação divisão, uma vez que esse está relacionado às estratégias utilizadas pelos alunos para lidar com o resto. $O$ objetivo dessa parte da pesquisa era observar e analisar o saber efetivamente ensinado, ou seja, a prática do professor e não as estratégias dos alunos que estão relacionadas ao saber aprendido. Assim, constatamos que P4 ensinou de forma satisfatória as divisões exatas e não exatas, cometendo equívocos apenas ao não colocar seus alunos na posição de pesquisador.

A interpretação dos resultados obtidos na divisão - pudemos verificar o trabalho com questões em que o quociente era a solução do problema (37 questões das 38 trabalhadas nas listas) e uma questão em que uma das soluções é o resto. Dessa maneira, evidenciamos o pouco trabalho com questões em que a solução é o resto. Diante do exposto, constatamos que P4 limita o saber a ensinar com relação à interpretação dos resultados obtidos na divisão, uma vez que se restringe praticamente ao trabalho com questões em que a solução é o quociente, quase não ensinando questões em que a solução é o resto e não ensinando questões em que a solução é o quociente mais um.

\section{$\underline{5^{\circ} \text { ano do ensino fundamental }}$}

Os diferentes procedimentos de cálculo - pudemos verificar o trabalho com 0 algoritmo euclidiano longo, a estratégia pessoal e o algoritmo euclidiano breve. Assim, a partir das análises das aulas de P5 pudemos verificar ainda lacunas no saber ensinado em relação ao saber a ensinar previsto nos documentos e no livro didático do $5^{\circ}$ ano relacionado aos diferentes procedimentos de cálculo, uma vez que constatamos a ausência de trabalho com os procedimentos de cálculos mental e o algoritmo americano. A falta do trabalho desses procedimentos pode acarretar prejuízos na aprendizagem, pois eles favorecem o desenvolvimento da estimativa e do cálculo mental. Vale destacar ainda o trabalho com o algoritmo euclidiano longo não previsto para ser ensinado de acordo com o livro didático do $5^{\circ}$ ano analisado.

Os significados da divisão — foram trabalhadas 23 questões, além dos exemplos dados e corrigidos por P5 e de duas listas de questões não contextualizadas. Dessas questões, pudemos 
constatar que 15 envolviam o significado da divisão partição, 4 questões o significado quotição e 4 questões que se encaixam na categoria de questões não contextualizadas.

Analisando tais dados fica nítido uma predominância do significado partição com 65,22\% das questões nas aulas de P5 e quando comparados com os dados da análise do LD do $5^{\circ}$ ano (questões de partição 35,29\%), verificamos um aumento de $29,93 \%$ na quantidade de questões de partição efetivamente trabalhadas em relação as previstas no LD. Isso decorre possivelmente também da não utilização por parte de P5 do LD e pelo significado partição envolver a ideia de repartir igualmente, sendo mais presente nos livros didáticos, segundo Selva (1998). Esse fato também como foi evidenciado na análise dos LD utilizados pelos participantes desta pesquisa. Cabe salientar que o percentual de questões de quotição e questões não contextualizadas foram $17,39 \%$ das questões em cada. Dessa maneira, verificamos que P5 promove mudanças no saber a ensinar (previsto no LD do $5^{\circ}$ ano e nos documentos), isto é, ele ensina, em sua maioria, questões de partição, não seguindo o previsto para ser ensinado no LD, no qual havia um certo equilíbrio entre as questões de partição e quotição a serem trabalhadas em sala de aula, o que pode acarretar prejuízos para aprendizagem de seus alunos.

O tratamento dado ao resto - observamos o trabalho com divisões exatas e não exatas. Dessa maneira, observamos que P5 ensinou o saber previsto para ser ensinado no LD e nos documentos analisados em relação ao tratamento dado ao resto na operação divisão, pois ensinou de forma satisfatória as divisões exatas e não exatas, de acordo com o LD e os documentos analisados. Vale destacar, ainda, um maior trabalho do professor com divisões não exatas do que o previsto no LD, bem como o não tratamento dado ao resto na operação divisão, uma vez que esse está relacionado, conforme já citado, às estratégias utilizadas pelos alunos para lidar com o resto. $O$ objetivo dessa parte da pesquisa era observar e analisar o saber efetivamente ensinado, ou seja, a prática do professor e não as estratégias dos alunos que estão relacionadas ao saber aprendido.

A interpretação dos resultados obtidos na divisão - verificamos o trabalho com questões em que a solução é o quociente e questões em que a solução é o resto. Vale frisar que das 23 questões trabalhadas em sala de aula por P5, em 22 delas a solução era o quociente e em 5 , a solução era o resto. Cabe ressaltar que em quatro dessas questões eram perguntadas as duas soluções (quociente e resto). Assim, observamos que P5 trabalhou com questões nas quais a solução é o quociente (conforme previsto para ser ensinado) e, também, com questões em que 
a solução é o resto (não previsto no LD do $5^{\circ}$ ano). Dessa maneira, constamos que P5 trabalha o saber previsto para ser ensinado e vai além do que previa o LD, ensinando questões em que a solução é o resto ponto positivo na sua prática.

\section{$\underline{6^{\circ} \text { ano do ensino fundamental }}$}

Os diferentes procedimentos de cálculo - verificamos o trabalho com os algoritmos euclidiano longo e breve nas aulas de P6. Desse modo, evidenciamos lacunas no saber ensinado em relação ao saber a ensinar previsto nos documentos e no LD do $6^{\circ}$ ano, tendo em vista que não observamos o trabalho com o procedimento de cálculo arredondamento previsto no LD do $6^{\circ}$ e nos documentos analisados. É importante frisar o trabalho com o algoritmo euclidiano breve não previsto para ser ensinado de acordo com o LD analisado.

Os significados da divisão - foram trabalhadas 29 questões. Observamos que dessas, 13 questões envolviam o significado da divisão partição, 8 questões o significado quotição e 8 questões que se encaixam na categoria de questões não contextualizadas.

Ao analisar tais dados fica evidente uma predominância do significado partição com $44,82 \%$ das questões nas aulas de P6; quando comparados com os dados da análise do LD do $6^{\circ}$ ano (questões de partição 61,11\%), verificamos uma diminuição de 16,29\% na quantidade questões de partição efetivamente trabalhadas em relação as previstas no LD. Observamos ainda que o percentual de questões de quotição e questões não contextualizadas foi de $27,59 \%$ das questões cada. Assim, percebemos que apesar de P6 ter ensinado de forma mais igualitária os significados da divisão partição e quotição do que o previsto no LD, ele ainda prioriza o significado partição em suas aulas. Dessa maneira, deixa lacunas no saber previsto para ser ensinado, uma vez que os dois significados merecem ser trabalhados igualmente em sala de aula.

O tratamento dado ao resto - verificamos o trabalho com divisões exatas e não exatas. Nas divisões exatas, P6 buscou trabalhar por meio das questões de suas listas não respondendo nenhuma, apenas solicitava que os alunos resolvessem, depois chamava-os para resolver no quadro e, a partir dessas resoluções, explicava como procederam na resolução de tais questões, ou seja, P6 subtendia possivelmente que os alunos sabiam já calcular divisões exatas. Enquanto nas divisões não exatas, P6 respondeu dois exemplos, visando mostrar os dois algoritmos já mencionados, bem como revisando divisões em que o resto é diferente de zero, isto é, divisões não exatas. Dessa maneira, P6 faz o caminho inverso do que defende Rosa dos Santos (2015), isto é, mostra como resolver sem colocar os alunos na condição de pesquisador restringindo a 
capacidade de pensar dos mesmos. Assim, verificamos que P6 ensinou o saber previsto para ser ensinado no LD e nos documentos analisados em se tratando do tratamento dado ao resto na operação divisão, cometendo alguns equívocos ao restringir a capacidade de pensar de seus alunos. É importante mencionar ainda que não houve tratamento dado ao resto, pois essa análise, como já destacamos, decorre das estratégias utilizadas pelos alunos.

A interpretação dos resultados obtidos na divisão - observamos o trabalho com questões em que a solução é o quociente e questões em que a solução é o resto. Vale destacar que apenas duas das 29 questões trabalhadas eram questões em que o resto era a solução. Dessa forma, notamos que P6 trabalha o saber previsto para ser ensinado de acordo com o LD e os documentos analisados. Contudo, constatamos o pouquíssimo trabalho com questões em que o resto é a solução da questão.

\section{Considerações}

A investigação, que ora concluímos, teve como principal objetivo analisar os principais aspectos relacionados ao processo de transposição didática interna da operação de divisão de números naturais no Ensino Fundamental com foco nas análises das aulas dos professores sujeitos da pesquisa.

Em síntese, constatamos que nenhum dos três professores ensinou integralmente o saber previsto para ser ensinado nos documentos legais analisados e livros didáticos, ou seja, transformaram o saber a ensinar em saber ensinado por meio de mudanças, deformações e deixando lacunas no saber previsto para ser ensinado, o que pode acarretar dificuldades nos alunos no processo de aprendizado da operação divisão de números naturais.

Outra informação importante decorrente da pesquisa é a ausência de utilização do LD pelos três professores, isto é, usavam fichas de atividades prontas ou escreviam no quadro, fato esse que pode ter contribuído para as mudanças, deformações e lacunas evidenciadas. É importante salientar que todos falaram na entrevista que utilizavam o LD, ou seja, todos tinham um saber escolar definido que deveria auxiliar na preparação de suas aulas.

Também observamos que nenhum dos três utilizou a calculadora no processo de ensino da operação divisão, o que é previsto nos documentos legais analisados.

Diante do exposto, concluímos que o processo de transposição didática interna decorrente 
da abordagem dos três professores participantes em relação ao saber a ensinar, a operação divisão de número naturais, ocorreu de forma diferente do que estava previsto nos documentos legais e livros didáticos, o que pode acarretar prejuízos para a aprendizagem de seus alunos, ou seja, diversos aspectos importantes na abordagem da divisão de números naturais poderão ficar ausentes das salas de aula.

A partir dos resultados desse estudo, vislumbramos outras questões sobre a presente temática, que ainda precisam ser respondidas, tais como: Qual o saber aprendido após o ensino da operação divisão de números naturais? Por que os professores não utilizam o livro didático? Será que a relação entre o saber a ser ensinado e o saber a ensinar se dá função do conteúdo a ser ensinado?

Essas e outras questões, que surgem a partir desta pesquisa, ficam como indicações para futuras investigações, a fim de, cada vez mais, aproximarmos de uma aprendizagem mais eficiente e significativa das operações fundamentais, de modo particular da operação divisão.

\section{Referências}

ALVES, Evanilson Landim. Menos com menos é menos ou é mais? Resolução de problemas de multiplicação e divisão de números inteiros por alunos do ensino regular e da Educação de Jovens e Adultos. 2012. 205f. Dissertação (Mestrado em Educação) - Centro de Educação. Universidade Federal de Pernambuco. Recife.

ARAUJO, Abrão Juvêncio. O ensino de Álgebra no Brasil e na França: estudo sobre o ensino de equações do $1^{\circ}$ grau à luz da Teoria Antropológica do Didático. 2009. 292f. Tese (Doutorado em Educação) - Centro de Educação. Universidade Federal de Pernambuco. Recife.

BENVENUTTI, Luciana Cardoso. A operação de divisão: um estudo com alunos de 5 a série. 2008. 61f. Dissertação (Mestrado em Educação). Universidade do Vale do Itajaí. Itajaí.

BESSA DE MENEZES, Marcus. Investigando o processo de transposição didática interna: o caso dos quadriláteros. 2004. 184f. Dissertação (Mestrado em Educação) - Centro de Educação. Universidade Federal de Pernambuco. Recife.

BORBA, Rute; SELVA, Ana Coelho Vieira. Alunos de $3^{\mathrm{a}}$ e $5^{\mathrm{a}}$ séries resolvendo problemas de divisão com resto diferente de zero: 0 efeito de representações simbólicas, significados e escolarização. In: REUNIÃO ANUAL DA ASSOCIAÇÃO NACIONAL DE PÓS-GRADUAÇÃO E PESQUISA EM EDUCAÇÃO, 29, 2006, Caxambu. Anais da 29a Reunião Anual da ANPEd. Caxambu: ANPEd, 2006, p. 1-18.

BORDET, David. Transposition didactique: une tentative d'éclaircissement. DEES, n. 110, p. 4552, sep. 1997. 
BRASIL. Ministério da Educação. Secretaria de Educação Básica. Base Nacional Curricular Comum: Brasília: MEC/SEB, 2017.

BRASIL. Ministério da Educação. Secretaria de Educação Fundamental. Parâmetros Curriculares Nacionais: Matemática. Brasília: MEC/SEF, 1997.

BRASIL. Secretaria de Educação Fundamental. Parâmetros Curriculares Nacionais: terceiro e quarto ciclos do Ensino Fundamental — Matemática. Brasília: MEC/SEF, 1998.

BRITO MENEZES, Ana Paula de Avelar. Contrato didático e transposição didática: interrelações entre os fenômenos didáticos na iniciação à Álgebra na 6a série do Ensino Fundamental. 2006. Tese. 259f. (Doutorado em Educação) - Centro de Educação. Universidade Federal de Pernambuco. Recife.

CÂMARA DOS SANTOS, Marcelo. O professor e o tempo. Revista Tópicos Educacionais, Recife, v. 15, n. $1 / 2$, p. 105-116, 1997.

CHEVALLARD, Yves. La transposicion didáctica: del saber sábio al saber enseñado. Traducción de de Claudia Gilman. Buenos Aires: Aique, 1991.

HENRY, Michel. Didactique des Mathématiques: sensibilizations à la didactique em vue de la formation initiale dês ensignants de mathématiques. Besançon: IPEM, 1991.

JOSSE, Elise. Analyse du discours des enseignanats. Paris: Presses UniversiteParis VII, 1992.

MATOS FILHO, Mauricio Ademir Saraiva; MENEZES, Josinalva Estácio; SILVA, Ronald de Santana da; QUEIROZ, Simone Moura. A transposição didática em Chevallard: as deformações/transformações sofridas pelo conceito de função em sala de aula. In: CONGRESSO NACIONAL DE EDUCAÇÃO, 8, 2008, Curitiba. Anais do VIII EDUCERE. Curitiba, PUC-PR, 2008, p. 1191-1201.

MENEZES, Marcus Bessa de. Investigando o processo de transposição didática interna: o caso dos quadriláteros. 2004. 184f. Dissertação de (Mestrado em Educação) - Centro de Educação. Universidade Federal de Pernambuco. Recife.

PERNAMBUCO. Secretaria de Estado da Educação. Base Curricular Comum para as Redes Públicas de Ensino de Pernambuco: Matemática. Recife: SEE, 2008.

PERNAMBUCO. Secretaria de Estado da Educação. Parâmetros para a Educação Básica do Estado de Pernambuco: Parâmetros Curriculares de Matemática para o Ensino Fundamental e Médio. Recife: SEE, 2012.

RAVEL, Laetitia. Des programmes à la classe: étude de la transposition didactique interne. Exemple de l'arithmétique em Terminale S spécialité mathématique. 2003. 290f. These (Doctorat en Didactique des Mathématiques) - Ecole Doctorale de Mathématiques et Informatique. Universidade Joseph Fourier. Grenoble.

ROSA DOS SANTOS, Marilene. A transposição didática do conceito de área de figuras geométricas planas no $6^{\circ}$ ano do Ensino Fundamental: um olhar sob a ótica da Teoria Antropológica do Didático. 2015. 281f. Tese (Doutorado em Ensino das Ciências) — Departamento 
de Educação. Universidade Federal Rural de Pernambuco. Recife.

SAIZ, Irma. Dividir com dificuldade ou dificuldade de dividir. In: PARRA, Cecília; SAIZ, Irma (Org.). Didática da Matemática: reflexões psicopedagógicas. Tradução de Juan Acuña Llorenas. Porto Alegre: Artmed, 2001, p. 162-191.

SELVA, Ana Coelho Vieira. Discutindo o uso de materiais concretos na resolução de problemas de divisão. In: SCHLIEMANN, Analúcia; CARRAHER, David William. (Org.). A compreensão de conceitos aritméticos: ensino e pesquisa. Campinas: Papirus, 1998, p. 95-119.

SELVA, Ana Coelho Vieira; BORBA, Rute; STEEDMAN, Lígia. Explorando a resolução de problemas de divisão com resto por crianças de $2^{a}$ e $3^{a}$ séries. In: ENCONTRO NACIONAL DE EDUCAÇÃO MATEMÁTICA, 8, 2004. Anais do VIII ENEM. Recife: SBEM, 2004, p. 1-19.

SOUZA, Kátia do Nascimento Venerando de. As operações de multiplicação e divisão nas séries iniciais do Ensino Fundamental. Revista de Iniciação Científica, Marília, v. 10, n. 1, p. 1-15, jan./abr. 2010.

VERGNAUD, Gérard. Teoria dos Campos Conceituais. In: BRUNN, Jean. (Ed.). Didáctica das Matemáticas. Lisboa: Horizontes Pedagógicos, 1996, p. 155-191. 